\title{
Effect of Esthetic Defects in Anterior Teeth on the Emotional and Social Well-being of Children: A Survey
}

\author{
Teena Gupta ${ }^{1}$, Gunmeen Sadana ${ }^{2}$, Hashmit K Rai ${ }^{3}$
}

\begin{abstract}
Objectives: This study aimed to determine whether imperfections in the anterior dentition affect the emotional and/or social well being of school going children in Amritsar district of Punjab, India.

Methods: A total of 2582 children between the ages 10 and 15 years of both genders were examined. Of these, 528 children with esthetic imperfections were asked a series of questions to assess their emotional and social disposition, with respect to children with no esthetic defects. Results: Females were more shy if they did not have a perfect anterior dentition $(p=0.000)$. Low socioeconomic status corresponded with gender (females) in determining emotional insecurity. Malocclusion was the most common cause of aesthetic defects ( $291 / 528$ children), followed by causes such as, hypoplasisa/ hypocalcification, stains, peg shaped, microdontia, congenitally missing (46.4\%), trauma (30.5\%) and caries (1.2\%). Irrespective of cause of defect, $53.8 \%$ of children were emotionally affected, in that, were fearful of being teased by other children (77.1\%).

Keywords: Anterior teeth, Esthetics, Psychological impact, School-going children, Social impact.

International Journal of Clinical Pediatric Dentistry (2019): 10.5005/jp-journals-10005-1628
\end{abstract}

\section{INTRODUCTION}

The concept of beauty has existed since the beginning of human mankind. The concept of aesthetics is strongly related to the concept of beauty, which complement each other. ${ }^{1}$ Van der Geld et al. remind us that the mouth is the center of communication in the face, calling the attention of the interlocutor. ${ }^{2}$

It is also known that the satisfaction degree toward the aesthetics of the mouth is related to the self-consciousness of an individual. ${ }^{3}$ Therefore, any defect in the anterior teeth may impair the outward appearance of that person. How this impairment affects the psychology of that human being is worth questioning.

Literature on the perception of defective anterior dentition on the psychology of adults may be found in abundance, but the same cannot be said so for the children. However, it has been suggested in the past that children with normal dental appearance were adjudged better looking, more desirable as friends, more intelligent, and less likely to behave aggressively. ${ }^{4}$ Albeit the requisite of dental aesthetics has been emphasized upon, ${ }^{5}$ it is surprising that the psychosocial impact of tooth appearance is a largely uncharted field. ${ }^{4}$

Defects in the anterior teeth, which affect the aesthetic appearance of an individual, may be the result of traumatic injuries, pulpal pathologies, dental caries, developmental disturbances, fluorosis, opacities, etc. ${ }^{6}$

Hence, this study was evoked to determine and quantify the factors associated with the emotional and/or social well-being of children with respect to defects in the anterior dentition.

\section{Subjects and Methods}

A total of 2,582 children between the age group of 10-15 years participated in this study.

Before the start of the study, permission was obtained from the Ethical Committee of the Institute (2017/ETH/2428). Preceding approval was acquired from the respective school authorities. Written parental consent along with the child's verbal consent was sought. A child's dissent superseded the parental consent.
${ }^{1-3}$ Department of Pedodontics and Preventive Dentistry, Sri Guru Ram Das Institute of Dental Sciences and Research, Amritsar, Punjab, India

Corresponding Author: Teena Gupta, Department of Pedodontics and Preventive Dentistry, Sri Guru Ram Das Institute of Dental Sciences and Research, Amritsar, Punjab, India, Phone: +91 9779595309, e-mail: teena4758@gmail.com

How to cite this article: Gupta T, Sadana G, et al. Effect of Esthetic Defects in Anterior Teeth on the Emotional and Social Well-being of Children: A Survey. Int J Clin Pediatr Dent 2019;12(3):229-232.

Source of support: Nil

Conflict of interest: None

The inclusion criteria consisted of absence of systemic and developmental disorders including syndromes/craniofacial abnormalities.

The study is divided into two parts:

- Clinical examination of the child's anterior teeth.

- Children's perception questionnaire regarding anterior teeth aesthetics.

In the first part of the study, the dental examinations were carried out by two pedodontists who were recruited for the study and were trained for the same. They were calibrated according to the protocol specified in the study's examination manual.

Examinations were carried out in the schools, with children to be examined seated on an ordinary chair under good illumination using either natural light or hand torch. Sterile mirrors and CPI probes were used for the examination, while taking protective cross-infection control measures, using gloves and masks. Dental radiographs were not involved in the examination.

The child's age, gender, and previous dental experience were enquired about. The factors affecting aesthetic appearance of the child were assessed according to predetermined criteria including clinical evidence of dental trauma, caries, external staining, malocclusion, and developmental disturbances. 
Based on the examinations, the children were divided into two groups:

- Children with esthetic defects

- Children without esthetic defects

During the examination, the examiner was unaware of the child's attitude toward the esthetic appearance of other children, which formed the second part of the study. In this part, the children were asked a series of questions from a well-structured questionnaire. The questioning was carried out in local languages. The proportion of students' response was expressed in absolute numbers.

The collected data were then subjected to statistical evaluation. Proportions were compared using the Chi-square test of significance.

\section{Results}

The number of children with esthetic defects in the anterior dentition was 528 (Table 1). Of all the children who had esthetic imperfections in teeth, 253 (47.9\%) were limited to the maxillary teeth, $13.8 \%$ had defects in the mandibular dentition, and $37.5 \%$ children presented defects in both arches. This distribution had no effect on the emotional or the social well-being of the participants, or the gender, or the socioeconomic level of the children.

Of the 528 children, 346 (65.5\%) were males. Females were found to be more shy if they had an esthetic defect when compared with males of the same age and this difference was highly significant $(p=0.000)$. Also, females who belonged to the lower socioeconomic status, i.e., $47.2 \%$ of the study sample, were more emotionally insecure when aesthetics were compromised owing to faulty anterior dentition.

Out of 519, 528 (98.3\%) children had anterior teeth that were caries free. Of the remaining, nine children who did have caries, three had carious lesions on the labial surface, two on the lingual surface, one interproximally, and three had caries that involved the whole of the tooth. Children with caries avoided school or leisure activities as compared to those without caries and this difference was statistically significant ( $p=0.000$; Table 2 ).

Another interesting finding was that the occurrence of caries had no predilection for a specific socioeconomic status or the parents' education level. Even though children with caries were shyer than children without caries, the difference was not statistically significant.

The most common cause of the anterior esthetic defect was found to be malocclusion (292/528 children). Of this $55.3 \%$ of the sample size, crowding was seen in $34.8 \%$, making it the most common defect in the anterior dentition. It was followed by a protrusion (11.4\%), spacing and increased overbite (2.5\% each), rotation (2.3\%), and increased overjet (1.9\%). However, the difference between perceptions of children toward other children with malocclusion and those without was not found to be statistically significant. In addition

Table 1: Number of observations and frequencies of the cause of aesthetic defect in anterior dentition in children $(n=528)$

\begin{tabular}{lcc}
\hline Variable & $n^{*}$ & $\%(C / 95 \%)$ \\
\hline Malocclusion & 292 & $55.3(51.06-59.54)$ \\
Trauma & 161 & $30.5(26.57-34.43)$ \\
Caries & 9 & $1.7(0.6-2.8)$ \\
Others & 245 & $46.4(42.15-50.65)$ \\
\hline
\end{tabular}

*Number of valid observations
Table 2: Effect of caries on the emotional and social well-being of children $(n=9)$

\begin{tabular}{lll}
\hline & $n^{*}(\%)$ & $p$-value \\
\hline Emotional well being & & \\
Shy & $8(88.9)$ & 0.021 \\
Concerned with what other people think & $5(55.6)$ & 0.571 \\
Worried about appearance & $8(88.9)$ & 0.099 \\
Social well being & & \\
Not wanting to speak/read loud in class & $4(44.5)$ & 0.798 \\
Avoid school or leisure activities & $5(55.6)$ & 0.000 \\
Do not want to spend time with children & $2(22.3)$ & 0.265 \\
Avoid smiling or laughing & $5(55.6)$ & 0.154 \\
Being teased by children & $4(44.5)$ & 0.124 \\
Being questioned by others & $2(22.3)$ & 0.661 \\
\hline
\end{tabular}

*Number of valid observations

to this finding, it was also discovered that the gender of the child did not influence his/her perception of aesthetics (Table 3).

Trauma to the anterior dentition was seen in 161, i.e., $30.5 \%$ of the children, of which, $21.8 \%$ sustained trauma to less than one-third of the crown, $6.8 \%$ involved trauma to one-third to twothirds of the crown, and $1.9 \%$, i.e., 10 children had experienced trauma that affected more than two-thirds of the clinical crown. These children were socially less confident as they were teased by other children. In contrast, children who had no traumatic incident and no subsequent defect in the anterior teeth were socially more adept and stronger. This difference was found to be statistically highly significant ( $p=0.000)$. Trauma as a cause of emotional or social well-being of the child had no statistically significant difference to exhibit when gender or parents' level of education was taken into account. Also, socioeconomic status had no role to play in the prevalence of trauma in children (Table 4).

Other causes of anterior esthetic defects included stains (35.8\%), hypoplasia/hypocalcification (7.8\%), peg-shaped teeth (1.5\%), microdontia (0.2\%), and congenitally missing teeth (0.4\%). Any other cause accounted for a meager $0.8 \%$ of the study sample.

About $49.2 \%$ children were shy if they had an esthetic defect, $53.8 \%$ were concerned with what other people might think of them if they had improper front teeth, $37.5 \%$ were worried about their appearance if they did not have a healthy anterior dentition. In the social well-being compartment, $48.7 \%$ did not want to speak/read

Table 3: Effect of malocclusion on the emotional and social well-being of children $(n=292)$

\begin{tabular}{lcc}
\hline & $n^{*}(\%)$ & $p$-value \\
\hline Emotional well being & & \\
Shy & $144(49.3)$ & 0.461 \\
Concerned with what other people think & $129(44.2)$ & 0.297 \\
Worried about appearance & $183(66.1)$ & 0.928 \\
Social well being & & \\
Not wanting to speak/read loud in class & $144(49.3)$ & 0.743 \\
Avoid school or leisure activities & $31(10.6)$ & 0.454 \\
Do not want to spend time with children & $27(9.2)$ & 0.202 \\
Avoid smiling or laughing & $91(31.2)$ & 0.240 \\
Being teased by children & $59(20.2)$ & 0.099 \\
Being questioned by others & $79(27.0)$ & 0.328 \\
\hline
\end{tabular}

*Number of valid observations 
Table 4: Effect of trauma on the emotional and social well-being of children $(n=161)$

\begin{tabular}{lrc}
\hline & $n^{*}(\%)$ & $p$-value \\
\hline Emotional well being & & \\
Shy & $83(51.6)$ & 0.809 \\
Concerned with what other people think & $84(52.2)$ & 0.069 \\
Worried about appearance & $109(67.7)$ & 0.102 \\
Social well being & & \\
Not wanting to speak/read loud in class & $88(54.7)$ & 0.068 \\
Avoid school or leisure activities & $24(14.9)$ & 0.110 \\
Do not want to spend time with children & $23(14.3)$ & 0.087 \\
Avoid smiling or laughing & $62(38.5)$ & 0.095 \\
Being teased by children & $54(33.5)$ & 0.000 \\
Being questioned by others & $57(35.4)$ & 0.026 \\
\hline
\end{tabular}

*Number of valid observations

loud in class, $88.4 \%$ avoided school or leisure activities, $89.2 \%$ did not want to spend time with other children, $66.7 \%$ avoided smiling or laughing, $77.1 \%$ were fearful of being teased by other children, and $71.2 \%$ were anxious about being questioned by other children if they did not have an esthetically pleasing anterior dentition.

Irrespective of the cause of the esthetic defect, $53.8 \%$ of children were concerned with what others would think of them if they did not have a proper anterior dentition. This percentage of children was found to be lagging behind their counterparts who had a proper anterior dentition, irrespective of the gender or the socioeconomic status, or the level of their parents' education and their jobs. This difference was statistically highly significant $(p=0.001)$.

\section{Discussion}

The findings, contained by the acknowledged restraint of the study design, suggest that on the basis of dental appearance, young people do make unconstructive opinions regarding other young people. ${ }^{7}$ To some degree, these findings were an anticipated product, given that many previous studies ${ }^{8-10}$ have also established that dental appearance differing from expected norms leads to negative social judgments being made.

In proportion to the child's developmental psychology, 6 years of age mark the launch of the abstract thinking and selfimage and concept. Children begin to judge against their physical features and individuality qualities with those of other children or against a norm. ${ }^{11}$ Therefore, the questioning of children about their appearances was justified in this study.

In the lower socioeconomic group, females were found to be more worried about their appearance. Also, males of the same group were less shy and did not tend to hold back if they had an esthetic defect. The difference in perceptions of females was different from males and this did not coincide with the findings of de Paula et al., who stated that even though the extent of gender as a variable in predicting the psychosocial impact of dental aesthetics has been considerable, it might be measured in the framework of the other significant variables. ${ }^{12}$ Other studies have established that women are more decisive of their opinion of impacts related to dental aesthetics. This might be a consequence of the usually reported a greater concern about health in women than in men, as expressed by higher attention to health care and greater wakefulness of oral health impacts, attractiveness attributed to facial appearance, and quality-of-life considerations. ${ }^{13,14}$ Factors associated with poverty, such as inadequate living conditions and malnutrition, may explain how socioeconomic status affects health. In return, health could serve as a predictor for socioeconomic status. This entails that over a certain stage of socioeconomic status, when housing and nutrition are not factors, persons should all exhibit comparable stratifications of good health. In addition, the greater part of explorations on socioeconomic status and health has focused on young to middleaged adults, with the extremes of the age spectrum receiving a lesser amount of consideration. Therefore, even though health problems in childhood constitute a noteworthy percentage of health-care costs, not as much is known about the impact of socioeconomic status on health during this age spectrum. ${ }^{15}$

Of the children affected by caries, the majority avoided going to school or leisure activities. This can be explained by the fact that pain is an established, direct outcome of dental caries and experiencing the condition of pain affect daily activities such as eating, brushing teeth, and sleep, all of which are important activities for the normal development of children and their health maintenance. ${ }^{16}$ In our study, children unaffected by caries were found to spend more time with other children and did not avoid smiling or laughing.

It is known that dissatisfaction with dental appearance is generally associated with the severity of irregularities. However, the recognition and the evaluation of these irregularities are different. ${ }^{17}$ That is, some patients may be content with malocclusions of severe grade, while others may be dissatisfied with minor irregularities. ${ }^{18,}$ ${ }^{19} \mathrm{O}^{\prime}$ Brien et al. ${ }^{14}$ suggested that it is the psychosocial domain that is most significantly affected when considering malocclusion as a factor affecting the quality of life rather than dissatisfaction with function. Phillips and Beal ${ }^{18}$ have demonstrated that adolescents pay more heed to the charisma or "positive" feelings toward the dentofacial region professed by self than the severity of the malocclusion-actual or perceived. This can explain why children quoted malocclusion as the foremost factor affecting their emotional and social well-being in our study.

The interest in assessing the impact of traumatic injuries to the teeth in this study can be justified by the fact that these injuries are very common and a majority of the injured teeth remain untreated or obtain insufficient management. ${ }^{20}$ Also, traumatic dental injuries may lead to pain, loss of function, and could harmfully influence the developing occlusion and aesthetics. These circumstances could negatively impact the children's lives. The teeth more frequently affected by trauma are the upper central incisors, possibly because of their position in the mouth. Furthermore, physical features such as an increased incisal overjet and anterior open bite have been reported as influencing factors of traumatic dental injuries. ${ }^{21}$ The results of our study collaborated with this finding as $69.5 \%$ of children were affected by trauma to the anterior dentition and being teased by other children affected them socially. Our findings corroborated with those of Bendo et al. ${ }^{22}$ and Schuch et al. ${ }^{16}$

The cause of esthetic defect other than trauma or caries or malocclusion included hypoplasia, hypocalcification, stains, peg morphology, microdontia, and congenitally missing teeth and was termed "other causes." Lower proportions of subjects reported emotional and social impacts as a result of congenitally missing teeth. This finding opposes that of Wong et al. ${ }^{23}$ and Locker et al. ${ }^{24}$

Interestingly, the level of education of the father or the mother had no impact on a child's emotional or social well-being in this study model. This finding was in opposition to that of Corwyn and Bradley. ${ }^{25}$ 


\section{Conclusion}

The present data indicate that imperfections in the anterior teeth impact negatively on the psychological and social well-being of children. It is postulated that research on awareness about oral health in children may help better define appropriate treatment and subsequent outcomes. This may prove beneficial not only for individual patients but also for community-based dental practices.

\section{References}

1. da Silva GC, Castilhos ED, et al. Dental esthetic self-perception of Brazilian dental students. RSBO 2012 Oct-Dec;9(4):375-381.

2. Van der Geld P, Oosterveld P, et al. Smile attractiveness. Angle Orthod 2007 Sep;77(5):759-765. DOI: 10.2319/082606-349.

3. Klages U, Bruckner A, et al. Dental aesthetics, self-awareness, and oral-related quality of life in young adults. Eur J Orthodont 2004 Oct;26(5):507-514. DOI: 10.1093/ejo/26.5.507.

4. Modi S, Williams L, et al. Development of an illustrated index of tooth appearance-perception-based quantification of tooth discolouration and surface defects. Int J Paediatr Dent 2010 Jul;20(4):293-304. DOI: 10.1111/j.1365-263X.2010.01053.x.

5. Goldstein RE. Esthetic dentistry - a health service? J Dent Res 1993 Oct;72(10):641-642. DOI: 10.1177/00220345930720031501.

6. Holan G, Rahme MA, et al. Parents' attitude toward their children's appearance in the case of esthetic defects of the anterior primary teeth. J Clin Pediatr Dent 2009 Winter;34(2):141-145. DOI: 10.17796/ jcpd.34.2.910037663v7pm6vg.

7. Craig SA, Baker SR, et al. Enamel defects in young patients. Int J Paediatr Dent 2015;25:399-408. DOI: 10.1111/ipd.12146.

8. Rodd HD, Abdul-Karim A, et al. Seeking children's perspectives in the management of visible enamel defects. Int J Paediatr Dent 2011 Mar;21(2):89-95. DOI: 10.1111/j.1365-263X.2010.01096.X.

9. Newton JT, Prabhu N, et al. The impact of dental appearance on the appraisal of personal characteristics. Int J Prosthodont 2003;16:429-434.

10. Williams DM, Chestnutt IG, et al. Characteristics attributed to individuals with dental fluorosis. Community Dent Health 2006;23:209-216.

11. Abanto J, Carvalho TS, et al. Impact of oral diseases and disorders on oral health-related quality of life of preschool children. Community Dent Oral Epidemiol 2011;39:105-114. DOI: 10.1111/j.16000528.2010.00580.x.
12. de Paula JS, Leite IC, et al. The impact of socioenvironmental characteristics on domains of oral health-related quality of life in Brazilian schoolchildren. BMC Oral Health 2013;13:10. DOI: 10.1186/1472-6831-13-10.

13. Hamdam AM. The relationship between patient, parent and clinician perceived need and normative orthodontic treatment need. Eur J Orthod 2004;26:265-271. DOI: 10.1093/ejo/26.3.265.

14. O'Brien CO, Benson PE, et al. Evaluation of a quality of life measure for children with malocclusion. J Orthod 2007;34:185-193. DOI: 10.1179/146531207225022185.

15. Chen E, Matthews KA, et al. Socioeconomic differences in children's health: how and why do these relationships change with age? Psychol Bull 2002;128:295-329. DOI: 10.1037/0033-2909.128.2.295.

16. Schuch HS, Costa Fdos S, et al. Oral health-related quality of life of schoolchildren: impact of clinical and psychosocial variables. Int J Paediatr Dent 2015;25:358-365. DOI: 10.1111/ipd.12118.

17. de Paula Júnior DF, Santos NC, et al. Psychosocial impact of dental aesthetics on quality of life in adolescents. Angle Orthod 2009;79:1188-1193. DOI: 10.2319/082608-452R.1.

18. Phillips C, Beal KNE. Self-concept and the perception of facial appearance in children and adolescents seeking orthodontic treatment. Angle Orthod 2009;79:12-16. DOI: 10.2319/071307-328.1.

19. Onyeaso CO, Sanu OO. Perception of personal dental appearance in Nigerian adolescents. Am J Orthod Dentofacial Orthop 2005;127: 700-706. DOI: 10.1016/j.ajodo.2003.12.028.

20. Cortes MI, Marcenes W, et al. Impact of traumatic injuries to the permanent teeth on the oral health-related quality of life in 12-14-year-old children. Community Dent Oral Epidemiol 2002;30:193-198. DOI: 10.1034/j.1600-0528.2002.300305.x.

21. Aldrigui JM, Abanto J, et al. Impact of traumatic dental injuries and malocclusions on quality of life of young children. Health Qual Life Outcomes 2011;9:78. DOI: 10.1186/1477-7525-9-78.

22. Bendo $C B$, Paiva $S M$, et al. Oral health-related quality of life and traumatic dental injuries in Brazilian adolescents. Community Dent Oral Epidemiol 2014;42:216-223. DOI: 10.1111/cdoe.12078.

23. Wong AT, McMillan AS, et al. Oral health-related quality of life and severe hypodontia. J Oral Rehabil 2006;33:869-873. DOI: 10.1111/j.1365-2842.2006.01654.x.

24. Locker D, Jokovic A, et al. Family impact of child oral and oro-facial conditions. Community Dent Oral Epidemiol 2002;30:438-448. DOI: 10.1034/j.1600-0528.2002.00015.x.

25. Bradley RH, Corwyn RF. Socioeconomic status and child development. Annu Rev Psychol 2002;53:371-399. DOI: 10.1146/annurev. psych.53.100901.135233. 